\title{
Using milk tanker pickup and weather station data to quantify the impacts of heat stress on milk production in Australia
}

\author{
$\underline{\text { R.S. Meyer }}^{\text {a }}{ }^{(D)}$, A-M Graham ${ }^{a}$, Hepworth, G. ${ }^{\text {b }}$ (D) and R.J. Eckard \\ ${ }^{a}$ Faculty of Veterinary and Agricultural Sciences, University of Melbourne Parkville Victoria \\ ${ }^{b}$ Statistical Consulting Centre, University of Melbourne Parkville Victoria \\ Email: meyer.r@unimelb.edu.au
}

\begin{abstract}
Due to high metabolic heat production, dairy cows are more sensitive to heat stress than other livestock. This has consequences on the animal's welfare and productivity. Reductions in milk production can occur from relatively mild temperatures with the degree of impact increasing with increasing severity of heat exposure. The degree to which heat stress impacts milk production, farm income, and milk supply is becoming increasingly important as the duration and frequency of heat waves increases. This analysis aims to provide estimates of the sensitivity of milk production on Australian dairy farms under heat stress situations.
\end{abstract}

The milk tanker pickup data from three dairy companies was used to investigate the on-farm impacts of heat stress on milk production in three regions of Australia. Milk production and weather data were matched based on the postcode of the farm and Bureau of Meteorology weather station. Weather data were used to calculate the temperature-humidity index (THI) using a formula typically used in Australian studies. The THI is commonly used to quantify the effects of heat stress by combining the effects of temperature and relative humidity. Data that did not meet pre-defined quality criteria were eliminated from the analysis. For instance, records that occurred three or more days since the previous milk pickup, data from farms with less than one year of observations, and years in which more than 10 records were missing between October and April, inclusive, were excluded. Over 960,000 records from 1,286 farms are included in the regional analysis. Linear mixed effect models were fitted to the data from each of three regions using $\mathrm{R}$.

The estimated response of milk volume (L) and milk solids ( $\mathrm{kg}$ ) and associated $95 \%$ confidence intervals (CIs) are summarised in Table 1. Models using THI values averaged over 7-days, consistently performed better than those averaged over shorter periods. THI values based on minimum and average temperatures performed slightly, but consistently, better than those based on maximum temperature.

Table 1. Change in milk production with increasing THI in three regions of Australia

\begin{tabular}{|c|c|c|c|}
\hline & Gippsland & Murray & SE QLD - NE NSW \\
\hline Volume (L/THI unit) $(95 \% \mathrm{CI})$ & $-13.7(-14.5,-12.8)$ & $-10.3(-11.3,-9.2)$ & $-10.8(-16.7,-4.9)$ \\
\hline Best performing THI metric & Min THI avg $7 \mathrm{~d}$ & Min THI avg $7 \mathrm{~d}$ & Min THI avg $7 \mathrm{~d}$ \\
\hline Milk Soli & $-1.38(-1.45,-1.32)$ & $-1.25(-1.32,-1.17)$ & $-0.66(-1.07,-0.25)$ \\
\hline Best performing THI metric & Avg THI avg $7 \mathrm{~d}$ & Avg THI avg $7 \mathrm{~d}$ & Min THI avg $7 \mathrm{~d}$ \\
\hline
\end{tabular}

The improved performance of average and minimum THI compared to maximum THI supports the hypothesis that cool night-time temperatures are important in mitigating the impacts of high daytime temperatures. THI metrics calculated over seven days, which performed better than those calculated over shorter periods, supports previous findings of lag effects and the impacts of prolonged heat. The larger impact of heat stress on milk production in Gippsland may reflect dairy cows being comparatively sensitive to heat in this relatively cool region, a lack of management interventions, or a combination of both. This analysis addresses the current losses associated with heat stress. This, accompanied by work on the cost effectiveness of available mitigation options, will assist in effective adaptation to the impacts of heat stress on dairies.

Keywords: Milk, heat stress, cows, production, temperature-humidity index 


\section{INTRODUCTION}

As the climate has warmed in the last several decades the frequency and severity of heatwaves has increased. For instance, the Australian Bureau of Meteorology and CSIRO (2016) reported that very warm monthly temperatures (defined as two standard deviations above the 1951-1980 average) occurred 2.2\% of the time during this period, and $11 \%$ of the time between 2001 and 2015. This was based on standardised data from 104 locations and all seasons. This trend is projected to continue. Warm spells, meaning six or more days above the $90^{\text {th }}$ percentile temperature from 1961 to 1990 , are projected to increase by more than 100 days per year by 2090 in a high emissions scenario (CSIRO and Bureau of Meteorology, 2015).

The agriculture sector is one of the most sensitive to heatwaves, experiencing wide-ranging effects. Impacts include reduced grain yield (Hochman et al., 2017), sunburn in fruit (Darbyshire et al., 2015), and reduced productivity and fertility in livestock systems (Harle et al., 2007; Tao and Dahl, 2013). Milk production can be quite sensitive to heat stress (Garner et al., 2017; Rhoads et al., 2009), as lactating animals have a greater metabolic heat load (Purwanto et al., 1990). However, the extent of the production losses caused by heatwave events in Australian dairying systems have received little attention in the scientific literature, impeding the ability make informed decisions regarding benefits and trade-offs of implementing management options of differing scales.

In 2018-2019 dairy was Australia's $4^{\text {th }}$ largest rural industry and had a farmgate production value of $\$ 4.4$ billion. The industry has a workforce of 46,200. Annual milk production of nearly nine billion litres occurs across 5,700 farms (Dairy Australia, 2019b). Much of this production is in Victoria. In 2019/2020 Victoria produced $64.9 \%$ of Australia's national milk production (Dairy Australia, 2021b). In the Gippsland region of southeast Victoria there are over 1,300 dairy farms producing $21 \%$ of the national production. In the Murray region, including northern Victoria and southern New South Wales, there are about 1,370 farms producing $22 \%$ of national production. Milk production occurs as far north as the subtropical region, which is comprised of over 500 farms and produces 6\% of the national production (Dairy Australia, 2021c).

Although the impacts of heat stress on milk production have been well researched globally, few studies have looked at the impacts of heat stress on Australian dairies. A chamber experiment addressed the sensitivity of Australian dairy cows and demonstrated reductions of $2.6 \mathrm{~L} / \mathrm{cow} /$ day $(12.5 \%)$ and $3.9 \mathrm{~L} / \mathrm{cow} /$ day $(17.4 \%)$ in heat tolerant and heat sensitive cows, respectively. This was observed with daily THIs ranging from 72 to 84 over four days (Garner et al 2016). In western Victoria, reductions in milk volumes observed during a heatwave in November 2009 ranged from as low as $0.3 \%$ on 17 farms near Timboon to $6.3 \%$ on 11 farms near Kolora and eight farms near Leslie Manor (Chang-Fung-Martel, 2020). An analysis of several annual datasets from New South Wales and Queensland found varying responses to heat stress (Mayer 1999), while another study addressed the impacts of heat stress on milk protein (Hayes et al., 2003).

This paper describes an analysis using dairy company milk tanker data to investigate the impacts of heat stress on milk yield in Australia. This is the first analysis to estimate the impacts heat stress has on milk yield using data from Australian farms over many years and over a significantly larger area than Chang-Fung-Martel (2020), including dairies from Gippsland, Victoria to Gladstone, Queensland.

\section{METHODS}

\subsection{Data and analysis}

Data: Tanker pickup records were obtained from three dairy companies and included milk volume, percent fat, percent protein, and cell count from 2000 to 2017. Approximately 36\% of this data was from 2-day pickups. Given this reduces the granularity of the response to heat stress, each record was labelled as a 1- or 2-day pickup to incorporate this effect into the analysis of the data. Records that occurred three or more days since the previous pickup were excluded from the analysis. In the rare cases where there was more than one pickup per day these were aggregated into a daily value.

For quality control purposes, other records excluded from the analysis were those from farms with less than one year of data and farm-years where more than 10 records were missing between October and April. Consequently, for inclusion, a farm had a minimum of at least 200 records. This was also applied to farms with 2-day pickups which led to those farms needing at least two years of data. No zero records were included; these values were treated as missing data as opposed to a pickup of 0 litres. This quality check of the milk production data was done using scripts written in R.

Farm data was connected to weather data based on postcodes. Weather stations used had consistent temperature and dew point data over the time series. The linking of farm postcodes with weather station postcodes was 


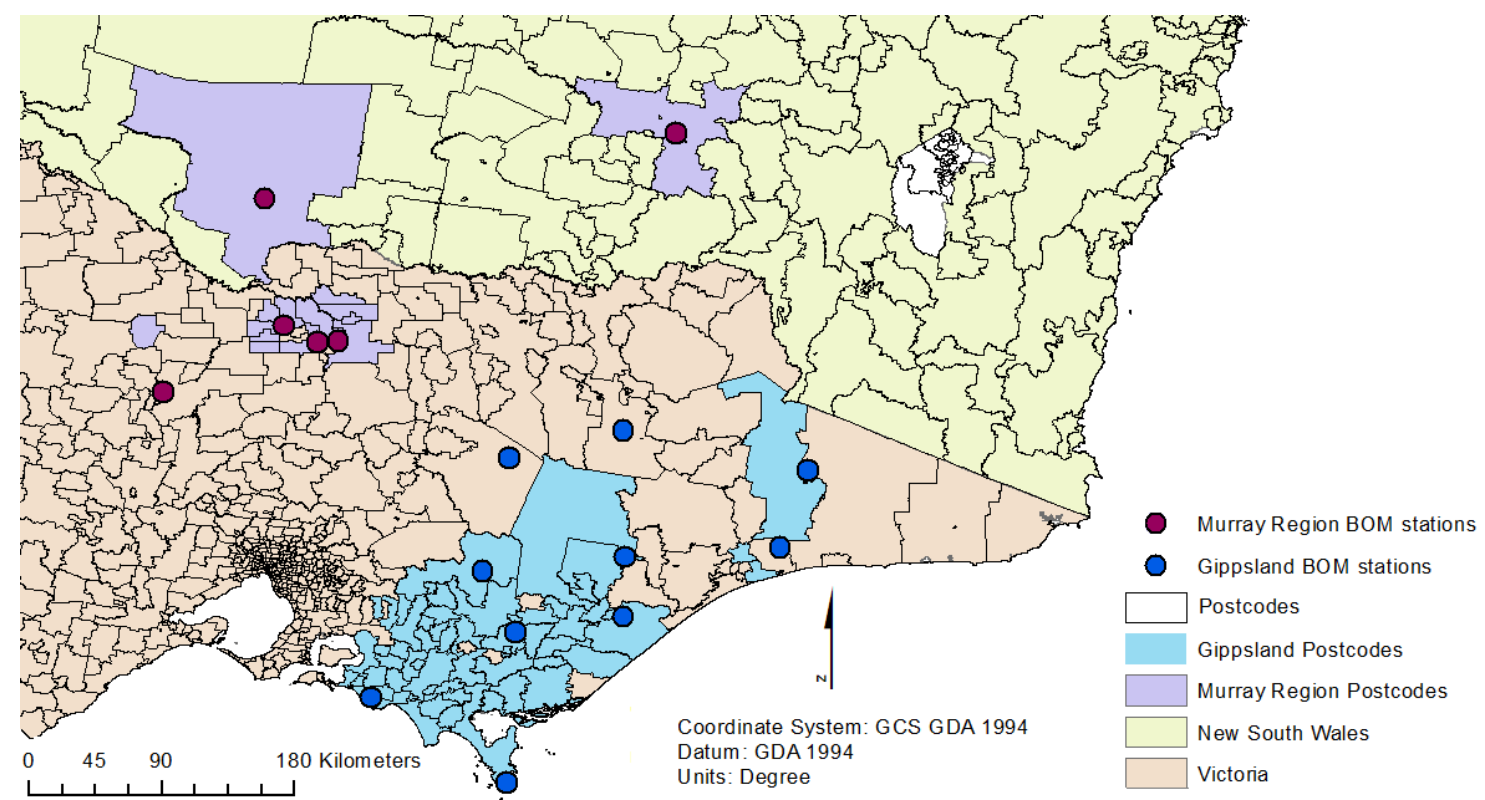

Figure 1. Postcodes with dairies included in the analysis and the associated BOM weather stations for the Gippsland and Murray regions

done using an Access database. Weather stations more than $50 \mathrm{~km}$ from the centre of the postcode were excluded to reduce the occurrence of using weather data far from farms; this was important

primarily for postcodes with large areas. Data from three regions of differing latitude with weather stations that had consistent dew point data are the focus of this analysis. Maps of the postcodes with milk tanker pickup data and weather stations were developed in ArcGIS and are shown in Figures 1 and 2.

Weather data was obtained from the Bureau of Meteorology (BOM) and included 3-hourly temperature and dew point temperature. The THI was calculated with a formula commonly used in Australia (Dairy Australia, 2019a) originally published by Yousef (1985):

THI $=$ Temp $_{A i r}+(0.36 *$ TempDewPt $)+41.2$
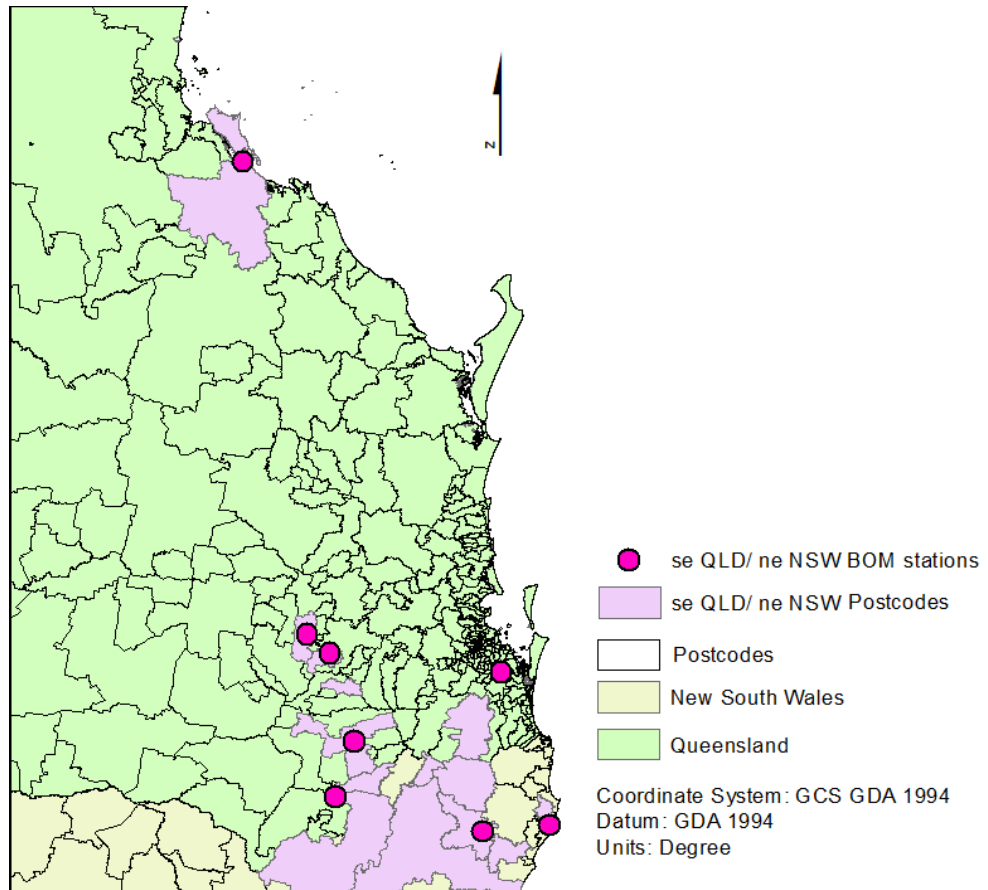

Coordinate System: GCS GDA 1994 Datum: GDA 1994 Datum: GDA 1994
Units: Degree

Figure 2. Postcodes with dairies included in the analysis and the associated BOM weather stations for southeast Queensland and northeast New South Wales regions

This data was used to determine daily minimum, daily average, and daily maximum THI. These values were then averaged over three, five and seven days to get 12 different THI measures, including the daily values.

Analysis: Linear mixed models were used to analyse the data. The random effects were farm (nested within postcode) and year (18 categories, i.e., the effect of time) and the fixed effects were the days since pickup (1 or 2), month (addresses the season, stage of lactation), and a measure of THI. The 12 THI metrics previously mentioned were investigated. This analysis was done in $\mathrm{R}$ using the lmer() function. Mixed models of increasing complexity were developed, incorporating more variables and more interactions 
between variables. Determination of the best performing THI metric was based on lowest $\mathrm{p}$-values, highest $\mathrm{R}^{2}$ and the lowest Akaike Information Criteria (AIC) scores. Models of increasing complexity were compared using residual maximum likelihood (REML), and comparison of identical models that used different measures of THI was made using maximum likelihood.

Three dairying regions were chosen to investigate how dairying areas with differing climatic characteristics respond to heat stress. These regions were Gippsland, the Murray River region, (Figure 1) and northeast New South Wales and southeast Queensland (Figure 2). This was done as opposed to including longitude in the mixed modelling since other characteristics of dairies vary with longitude. Inferring the extent to which variables such as forage type, management differences, and climate differences would impact the response to longitude was not possible with the lack of information on individual farms. The number of postcodes and farms from each of these regions included in the analysis is displayed in Table 2.

Table 2. Milk tanker data included in the analysis

\begin{tabular}{|c|c|c|c|}
\hline & Number of Postcodes & Number of Farms & Number of records \\
\hline Gippsland & 51 & 849 & 631,521 \\
\hline Murray & 14 & 388 & 323,465 \\
\hline SE QLD - NE NSW & 13 & 49 & 5456 \\
\hline
\end{tabular}

\section{RESULTS}

Two-day pickups reduced milk yield per farm per day. This reduction was $36.5,51.5$, and $53.5 \mathrm{~kg}$ milk solids in southeast Queensland - northeast New South Wales, Gippsland, and Murray regions, respectively. The reduction in volume was 504, 670, and 718 litres in southeast Queensland - northeast New South Wales, Gippsland, and Murray regions, respectively.

The impact of month reflects the lactation curve and predominance of spring calving in these regions. Milk production was greatest in October and declined through April. The decline in production over the summer is displayed in Figure 3 for the three regions.

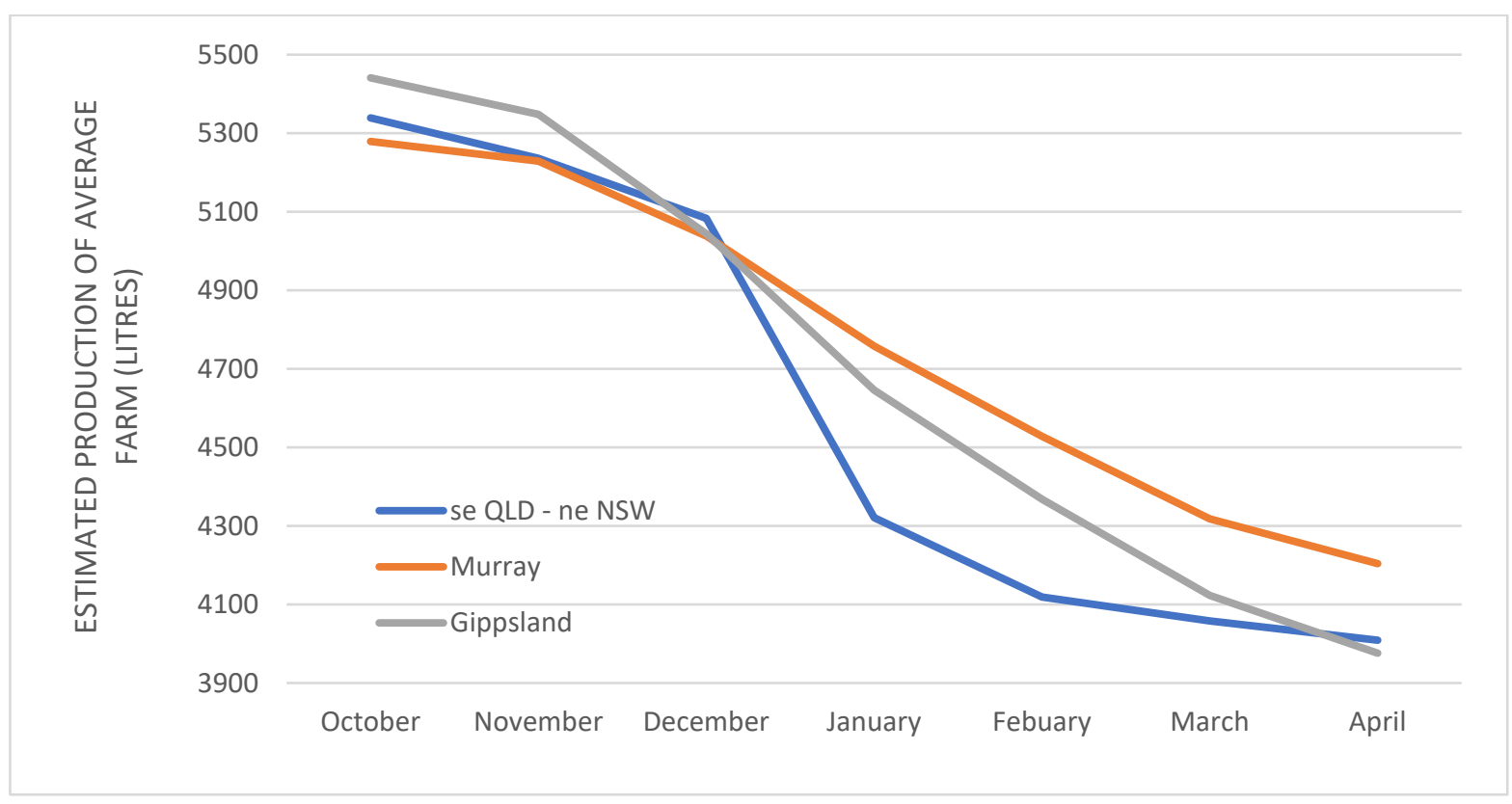

Figure 3. Change in milk production from spring calving peak in October to April in three regions of Australia.

In southeast Queensland and northeast New South Wales, both milk volume and milk solids were most strongly correlated to minimum THI averaged over seven days $(P<0.002)$. The minimum THI averaged over seven days ranged from 50.3 to 70.9 between October and April and averaged 62.7. Milk volume decreased by 10.8 litres per unit increase in this THI metric (Figure 4), with the 95\% confidence interval (CI) ranging from a reduction 
of $16.7 \mathrm{~L}$ to $4.9 \mathrm{~L}$. There was a reduction of $0.66 \mathrm{~kg}$ milk solids per unit increase in this THI metric (95\% CI $=-1.07$ to -0.25$)$. A summary of the milk yield response for both volume and milk solids for each region is

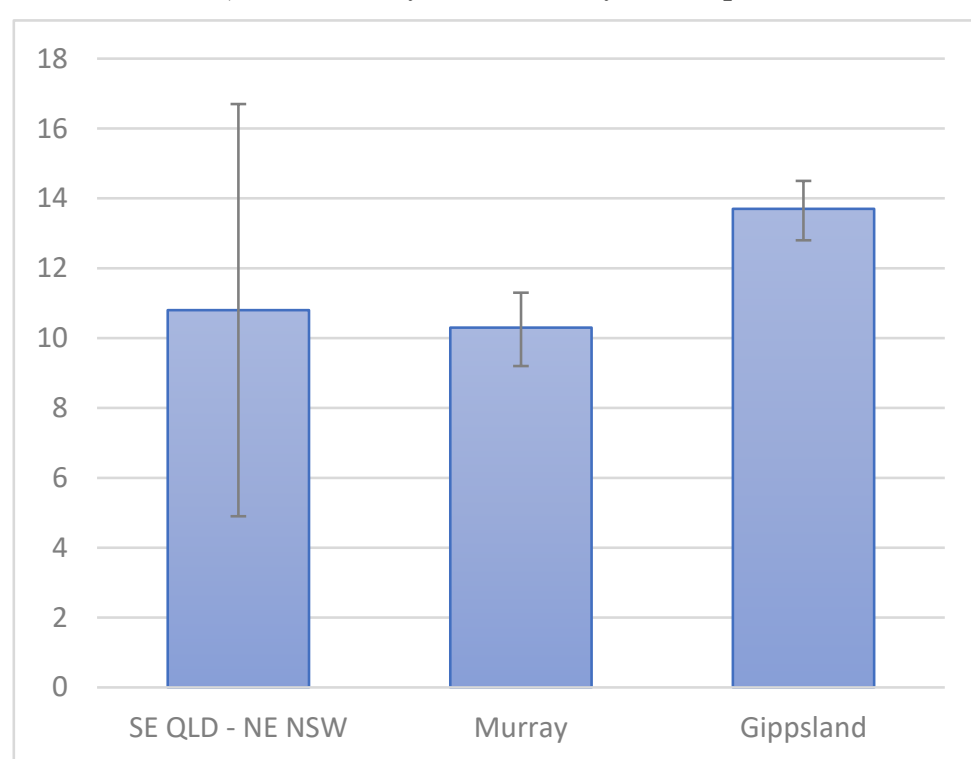

Figure 4. Average reduction in milk volume production per unit change in the minimum THI averaged over seven days in the three regions. The error bars show $95 \%$ CIs.

provided in Table 1 .

In the Murray Region of New South Wales and Victoria, milk volume and milk solids were most strongly correlated with the minimum THI averaged over seven days and the average THI over seven days, respectively $(P<0.001)$. In this region, the 7-day average THI ranged from 51.4 to 76.5 between October and April and averaged 63.7. There was a reduction of $1.25 \mathrm{~kg}$ in milk solids per unit increase in this THI metric $(95 \% \mathrm{CI}=-1.32$ to -1.17$)$. In this region the minimum $\mathrm{THI}$ averaged over seven days ranged from 38.7 to 71.4 from October to April with an average of 53.5. Milk volume was reduced by 10.3 litres per unit increase in this THI metric $(95 \% \mathrm{CI}=-11.3$ to -9.2 ; Figure 4$)$.

THI metrics that were most strongly correlated to milk production and milk solids in the Gippsland region were like the Murray Region, with milk volume most strongly linked to minimum THI averaged over seven days and milk solids most strongly related to 7-day average THI $(\mathrm{P}<0.001)$. The 7-day average THI ranged from 50.3 to 70.8 from October to April in Gippsland and averaged 60.2 . There was a reduction of $1.38 \mathrm{~kg}$ milk solids per unit increase in this THI metric $(95 \% \mathrm{CI}=-1.45,-1.32)$. In Gippsland, the minimum THI averaged over seven days ranged from 35.0 to 68.3 from October to April and averaged 52.5. Milk volume was reduced by 13.7 litres per unit increase in this THI metric $(95 \% \mathrm{CI}=-14.5$ to -12.8 ; Figure 4$)$.

\section{DISCUSSION}

The impact of heat stress per unit THI across the differing regions were generally similar for both milk volume and milk solids. However, the results suggest larger reductions in milk production with heat stress in Gippsland than in the Murray region. This suggests that either cows in these areas are more sensitive to heat stress or fewer management interventions are used in the cooler Gippsland region, or both. The wide confidence intervals associated with the southeast Queensland - northeast New South Wales estimates are primarily due to the smaller sample size from this area.

Across all regions the longer 7-day average of THI was a better predictor of heat stress impacts than averages over shorter periods. This result was consistent across regions and THI metrics (minimum, average, maximum), suggesting that milk production is most sensitive to heat exposure over long periods. THI averaged over longer period also captures lag effects which have been demonstrated in several studies. An Australian study found impacts of heat stress on milk production up to four days after exposure (Mayer et al., 1999). A lag effect of heat was detectable up to eight days in test day records from Italy (Bernabucci et al., 2014).

Maximum THI performed comparatively poorly across sites and productivity metrics (volume vs milk solids). This supports the contention that cool night-time temperatures can offset impacts of high daytime temperatures. Maximum THI was outperformed by average THI in studies in northwest Germany (Brügemann et al., 2012), Luxemburg, Slovenia, Spain (Carabano et al., 2016), and in the humid southeast USA (West et al., 2003). Carabano et al. (2016) suggested this is due to average THI incorporating the effect of cool nights which offsets the impacts of hot days.

Limitations: This analysis has two primary limitations: i) the lack of information on individual cows and farms that could influence heat stress response and ii), varying distances between the farms and the paired weather station. The second of these limitations was addressed to some extent by ensuring weather stations were within $50 \mathrm{~km}$ of the centre of the postcode. The size of postcodes means most farms are less than $50 \mathrm{~km}$ from the utilised weather station. This should provide a reasonable estimate of the weather experienced by cows. 
Previous analysis has shown weather stations over $200 \mathrm{~km}$ from the farm can provide satisfactory data for a broad-level analysis (Freitas, 2006).

Given the locations of the weather stations, the largest discrepancies are likely in cases where the station is near the coast and the associated farm is somewhat inland (e.g., the southernmost station in Figure 1 and the northern most station in Figure 2). This is more likely an issue for the southeast Queensland - northeast New South Wales dataset due to its smaller sample size and may contribute to the higher variability in the milk yield response. Since the de-identified milk tanker pickup data did not include exact farm locations and the THI calculation required consistent dew point measurements, single weather station data was used instead of the interpolated gridded dataset despite the limitations associated with distance between some farms and weather stations.

The lack of factors in the analysis that represent farm level characteristics, including heat stress management, also contribute to the regional-level focus of this analysis. Without more fine-grained information it is not possible to determine farm level factors that could reduce impacts of heat stress on milk production. An analysis of heat stress impacts on milk production in western Victoria found notable variation in production response at the subregional level (Chang-Fung-Martel, 2020). It is important to note that this analysis is only addressing the direct loss of milk production to heat stress and no other impacts of heat stress, including those on animal welfare and pasture availability.

Implications: Heat stress is already impacting dairy operations. The average milk solids response reported in this analysis, suggests a loss of $49 \mathrm{~kg}, 84 \mathrm{~kg}, 98 \mathrm{~kg}$ of milk solids per average farm with a 10 -unit increase in the relevant THI metric occurring over seven days for the southeast Queensland - northeast New South Wales, Murray, and Gippsland regions, respectively (e.g., 1.4*10*7 =98 in the case of the Gippsland region). Over a region the size of Gippsland this equates to a reduction of approximately 83,200 kg of milk solids (based on the 849 farms included in this analysis) and a financial loss of $\$ 499,200$ to the region's dairy industry, assuming the 2015-2020 average Victorian milk price of \$6/kg milk solids (Dairy Australia, 2021a). This represents a substantial challenge to farmers and the dairy industry. Such estimates assist with cost benefit analysis which is necessary to inform decisions regarding investments in farm infrastructure that can alleviate impacts. A clear understanding of the effectiveness of different interventions is also needed. Without action, these impacts are expected to worsen as the duration and frequency of heatwaves increase with climate change.

This analysis implies that although milk production in the subtropical north may be affected by heat for much of the year, cows in the cooler climate in Gippsland are more impacted by individual heat waves. Improved performance of THI metrics over longer time frames demonstrate the importance of cumulative impacts and lag effects on milk production. Better performance of averages and minimum THI metrics over maximums, imply that cool nights can offset the impacts of high day-time temperatures. These findings are important for both productivity and animal welfare considerations.

\section{ACKNOWLEDGMENTS}

This project (LWR/2014/072) is supported by funding from the Australian Government Department of Agriculture, Water, and the Environment as part of its Rural R\&D for Profit program, round three (codes MLA B.CCH.8110 and RnD4Profit-16-03-00). The authors acknowledge contributions, primarily with $\mathrm{R}$ support, from Cameron Patrick at the University of Melbourne's Statistical Consulting Centre and Rory Townsend.

\section{REFERENCES}

Bernabucci, U., Biffani, S., Buggiotti, L., Vitali, A., Lacetera, N., Nardone, A., 2014. The effects of heat stress in Italian Holstein dairy cattle. Journal of Dairy Science 97(1) 471-486.

Brügemann, K., Gernand, E., König von Borstel, U., König, S., 2012. Defining and evaluating heat stress thresholds in different dairy cow production systems. Archives Animal Breeding 55(1) 13-24.

Bureau of Meteorology, CSIRO, 2016. State of the Climate 2016. Commonwealth of Australia, 23. http://www.bom.gov.au/state-of-the-climate/State-of-the-Climate-2016.pdf

Carabano, M.-J., Logar, B., Bormann, J., Minet, J., Vanrobays, M.-L., Diaz, C., Tychon, B., Gengler, N., Hammami, H., 2016. Modeling heat stress under different environmental conditions. Journal of Dairy Science 99(5) 3798-3814.

Chang-Fung-Martel, J., 2020. Effects of Extreme Events on the Productivity of Dairy Farms, Tasmanian Institute of Agriculture. University of Tasmania: Hobart, Tasmania, p. 128 
CSIRO, Bureau of Meteorology, 2015. Chapter 7: Projections: Atmosphere and the land, Climate Change in Australia Information for Australia's Natural Resource Management Regions: Technical Report. CSIRO and Bureau of Meteorology: Australia.

Dairy Australia, 2019a. Cool Cows: Strategies for Managing Heat Stress in Dairy Cows. Dairy Australia, 47.

Dairy Australia, 2019b. Production \& Statistics. https:/www.dairyaustralia.com.au/industrystatistics/industry-reports/production-and-sales-statistics\#.YRjbwegzaUk [15/08/2021]

Dairy Australia, 2021a. Farmgate Milk Price. https://www.dairyaustralia.com.au/industry-statistics/farmgatemilk-price\#.YQfBDOgzaUk [15/08/2021]

Dairy Australia, 2021b. National Milk Production Report May 2021. Dairy Australia, https://www.dairyaustralia.com.au/resource-repository/2020/09/25/milk-production-report\#.YRjdTgzaUk

Dairy Australia, 2021c. Our regions. https://www.dairy.com.au/our-industry-and-people/our-regions $[15 / 08 / 2021]$

Darbyshire, R., McClymont, L., Goodwin, I., 2015. Sun damage risk of Royal Gala apple in fruit-growing districts in Australia. New Zealand Journal of Crop and Horticultural Science 43(3) 222-232.

Garner, J., Douglas, M., Williams, S., Wales, W., Marett, L., DiGiacomo, K., Leury, B., Hayes, B., 2017. Responses of dairy cows to short-term heat stress in controlled-climate chambers. Animal Production Science 57(7) 1233-1241.

Harle, K., Howden, S., Hunt, L.P., Dunlop, M., 2007. The potential impact of climate change on the Australian wool industry by 2030. Agricultural Systems 93(1-3) 61-89.

Hayes, B., Carrick, M., Bowman, P., Goddard, M.E., 2003. Genotype×Environment Interaction for Milk Production of Daughters of Australian Dairy Sires from Test-Day Records. Journal of Dairy Science 86(11) 3736-3744.

Hochman, Z., Gobbett, D.L., Horan, H., 2017. Climate trends account for stalled wheat yields in Australia since 1990. Global Change Biology 23(5) 2071-2081.

Mayer, D., Davison, T., McGowan, M., Young, B., Matschoss, A., Hall, A., Goodwin, P., Jonsson, N., Gaughan, J., 1999. Extent and economic effect of heat loads on dairy cattle production in Australia. Australian Veterinary Journal 77(12) 804-808.

Purwanto, B., Abo, Y., Sakamoto, R., Furumoto, F., Yamamoto, S., 1990. Diurnal patterns of heat production and heart rate under thermoneutral conditions in Holstein Friesian cows differing in milk production. The Journal of Agricultural Science 114(2) 139-142.

Rhoads, M., Rhoads, R., VanBaale, M., Collier, R., Sanders, S., Weber, W., Crooker, B., Baumgard, L., 2009. Effects of heat stress and plane of nutrition on lactating Holstein cows: I. Production, metabolism, and aspects of circulating somatotropin. Journal of Dairy Science 92(5) 1986-1997.

Tao, S., Dahl, G., 2013. Invited review: heat stress effects during late gestation on dry cows and their calves. Journal of Dairy Science 96(7) 4079-4093.

West, J., Mullinix, B., Bernard, J., 2003. Effects of hot, humid weather on milk temperature, dry matter intake, and milk yield of lactating dairy cows. Journal of Dairy Science 86(1) 232-242.

Yousef, M.K., 1985. Stress physiology in livestock. Volume I. Basic principles. CRC press. 